\title{
Unique Considerations for the Pediatric Athlete During Rehabilitation and Return to Sport After Anterior Cruciate Ligament Reconstruction
}

\author{
Yukiko Matsuzaki, P.T., D.P.T., Danielle E. Chipman, B.S., Sofia Hidalgo Perea, B.S., and \\ Daniel W. Green, M.D., M.S., F.A.C.S.
}

\begin{abstract}
Anterior cruciate ligament (ACL) injuries and surgical intervention in the pediatric population have increased in the recent years. Although surgical techniques have advanced, evidence-based rehabilitation guidelines that consider all aspects of the youth athlete are currently lacking. The purpose of this commentary is to review the current evidence on unique considerations for the pediatric and adolescent population during rehabilitation and return to sport after ACL reconstruction (ACLR), with a focus on children under 18 years of age. This review revealed that returning a youth athlete to sport after ACLR requires knowledge and appreciation of various aspects of the growing athlete different from adults. In addition to postoperative precautions that contribute to a slow rehabilitation process, young athletes need additional time for strength gains. Address risk of reinjury and for contralateral injury by using neuromuscular training and rigorous return-to-sport training programs. Consider return to sport after 9 months because the reinjury rate is high in this population. A combination of time and objective measures, both quantitative and qualitative criteria, and psychological readiness should be used to assess readiness to return to sport and decrease risk of future injury. Healthcare providers should be aware of the psychosocial impact of injury on the youth athletes and refer to sport psychology when necessary. Level of Evidence: Level V.
\end{abstract}

$\mathbf{O}$ ver the last 2 decades, anterior cruciate ligament (ACL) injuries and surgical intervention in children and adolescents have been increasing. ${ }^{1-7}$ This increase is often attributed to increased participation in competitive organized sports, ${ }^{8}$ early sports specialization, ${ }^{9}$ and year-round training and competition. ${ }^{10}$ Furthermore, advancements in surgical techniques allow for early reconstruction of the ACL in the

From the Department of Pediatric Rehabilitation, Department of Sports Rehabilitation and Performance, Hospital for Special Surgery (Y.M.), New York; and the Department of Pediatric Orthopedic Surgery, Hospital for Special Surgery (D.E.C., S.H.P., D.W.G.), New York, New York, U.S.A.

The authors report the following potential conflicts of interest or sources of funding: D.W.G. reports royalties from Anthrex, Inc., and Pega Medical; consulting fees from Anthrex, Inc.; and other from Current Opinion in Pediatrics and Wolters Kluwer Health. Full ICMJE author disclosure forms are available for this article online, as supplementary material.

Received August 3, 2021; accepted September 27, 2021.

Address correspondence to Daniel W. Green, M.D., M.S., F.A.C.S., Hospital for Special Surgery, 535 E 70th Street, New York, NY, 10021. E-mail: greendw@hss.edu

Published by Elsevier on behalf of the Arthroscopy Association of North America. This is an open access article under the CC BY-NC-ND license (http://creativecommons.org/licenses/by-nc-nd/4.0/).

2666-061X/211128

https://doi.org/10.1016/j.asmr.2021.09.037 skeletally immature patient, restoring knee stability, decreasing risk of subsequent injury to the knee, improving rate of return to play, and providing favorable long-term outcomes. ${ }^{1-14}$

Although pediatric athletes return to sports at a high rate after ACL reconstruction (ACLR), ${ }^{15}$ subsequent ACL injuries to the ipsilateral or contralateral leg are reported to be as high as $32 \% .^{16,17}$ Recent studies of revision ACLR in pediatric and adolescent populations have reported lower functional outcomes, lower return to sport rates, significant risk of contralateral ACL injury, and high rates of revision graft injury ${ }^{18,19}$ compared to primary ACLR. Revision ACLR has also been associated with more meniscal and cartilage abnormalities, ${ }^{18-20}$ which increases concern for long-term knee and general health.

Youth are undergoing changes both physiologically and psychologically which warrant consideration. As such, protocols and recommendations created for adults cannot merely be extrapolated to children and adolescents with ACL injuries. Physiologically, pediatric athletes have slower strength recovery, decreased neuromuscular control, poor rates of passing return-tosport (RTS) criteria, and higher reinjury rates than adults, suggesting that RTS testing criteria and timeline 
to RTS created for adults may not be appropriate. Sports also offers many psychosocial benefits for the youth including socialization, building teamwork and leadership skills, and improving self-esteem. ${ }^{21}$ Not being able to play has significant impact on the youth athlete physically, mentally, and socially. Therefore healthcare providers must not only ensure full recovery and RTS but also minimize the risk of reinjury. The purpose of this commentary is to review the current evidence on unique considerations for the pediatric and adolescent population during rehabilitation and RTS after ACL reconstruction (ACLR), with a focus on children under 18 years of age.

\section{ACL Injuries in Children and Adolescents}

The number of ACL injuries have been increasing across all age groups, even in children as young as 5 to 10 years of age. ${ }^{2-4,6,22}$ In children younger than 12 , a higher ACL injury rate is reported in boys. ${ }^{1,2,23-25}$ Increased rates in female athletes begin around puberty, ${ }^{1,24}$ at around age 12 . In both sexes, the rate of ACL injuries increase as they progress through puberty. ${ }^{1,2,4,24}$ The overall injury rate is highest in late adolescence for both sexes (15-18 years). ${ }^{1-4}$

Periods of rapid growth and development may contribute to ACL injury risk. The femur and tibia grow at a fast rate, which creates a longer lever and increases torque at the knee. $^{26}$ Increases in height and body weight raise the center of mass, and greater muscle forces are required to control its movement during sports activities leading to increased muscular and neuromuscular demand. ${ }^{26}$ After maturity, decreased biomechanical and neuromuscular control of the knee, such as greater knee abduction angles and moments, higher ground reaction forces during landing, and decreased active knee joint stiffness are observed in females compared to males. ${ }^{27-30}$

In addition to physical growth, sensorimotor mechanisms such as visual, somatosensory, vestibular, postural control, and coordination continue to develop during childhood and adolescence. Some adolescents may experience delays or regression in some aspects of sensorimotor function, which may affect motor control and contribute to awkward movement patterns. However, there is no consensus on how it may affect injury risk. ${ }^{31}$ These physical, biomechanical, neuromuscular, and sensorimotor factors may also contribute to a challenging rehabilitation compared to the adult population.

Nonoperative or delayed surgical treatment was once the standard of care for the skeletally immature patient with ACL tear due to concerns of physeal injury and subsequent deformity. Current practice has evolved to favor early surgery with good functional outcomes, decreased meniscal and articular cartilage injuries, and improved rate of return to sports with minimal risk of growth disturbance. ${ }^{11,14,32-35}$ Surgical treatment for the skeletally immature includes physeal sparing, partial transphyseal, and transphyseal techniques. ${ }^{10,12}$ Despite these advancements in surgical treatment, there is currently a lack of evidence-based rehabilitation protocols after ACLR specific to the youth athlete. ${ }^{36}$

\section{Psychosocial Considerations for the Youth Athlete}

Adolescence is a time for identity development, social skill acquisition, and developing independence. ${ }^{37}$ Professionals caring for the adolescent athlete must appreciate the impact of injury beyond physical symptoms and functional limitations. Lower quality-of-life (QOL) scores are reported in adolescent athletes with knee injuries ${ }^{38,39}$ with greater impairments in seasonending injuries such as ACL tears. ${ }^{40}$ A strong correlation between knee function and the social and emotional domains of QOL in pediatric and adolescent patients with ACL injuries has been found both before and after surgery. ${ }^{41}$ In addition to physical limitations, ACL-injured athletes may experience emotional reactions such as loss, denial, frustration, and anger, ${ }^{42-44}$ decreased academic performance, ${ }^{45}$ and loss of identity and loneliness. ${ }^{40,43,46}$ Although higher levels of athletic identity are associated with positive health benefits, self-esteem, and improved social relationships, they are also associated with depressive symptoms after injury. ${ }^{47}$ Moreover, Padaki et al. ${ }^{48}$ reported that many adolescent athletes experienced symptoms consistent with post-traumatic stress disorder after an ACL rupture, suggesting that the level of psychological trauma experienced by these athletes may be greater than is recognized. Healthcare professionals must appreciate the unique psychosocial factors that impact injured youth athletes and should prioritize their psychological and emotional well-being when caring for their physical health. To maintain social aspects, young athletes may be encouraged to attend and participate in their team training sessions as their surgical precautions allow. ${ }^{49}$ Although depressive symptoms may decrease over time, ${ }^{44,50}$ psychological response after an injury varies among individuals ${ }^{44}$; therefore referral to sport psychology may be warranted for the struggling athlete for successful rehabilitation.

Psychological factors must also be considered during recovery after ACLR. Factors such as anxiety may affect recovery in children. High levels of preoperative anxiety in children and adolescents are related to higher postoperative pain intensity. ${ }^{51}$ Perioperative parental anxiety and pain catastrophizing also relate to child anxiety and postoperative pain, ${ }^{52-54}$ highlighting the influence of parents on the child, unique to this population. Anxiety and pain can negatively affect rehabilitation because patients may not tolerate 
weightbearing loads and range of motion progressions and may find it difficult to adhere to home exercise programs or to be motivated. Youth athletes, especially prepubescents, cannot perform unsupervised exercises independently with correct technique. ${ }^{49}$ Successful rehabilitation and adherence to home programs often require collaboration with parents or family members, even in the adolescent population.

The healthcare team plays an important role for youth during their recovery. Disanti reported psychological and social barriers were just as prevalent as physical symptoms for returning to physical activity. Positive factors that help with recovery include having detailed knowledge of their recovery process, trusting relationships with the physical therapist (PT), individualized goals, and incorporating sport-specific activities. Negative factors include lack of attention from the medical team and receiving a generalized approach to treatment. ${ }^{42}$ Paterno et al. $^{55}$ identified PT/patient relationship quality as an essential factor that young patients and their parents perceive to impact ACLR outcomes. PTs are identified as a guide throughout the recovery process, motivator, confidence booster, and care coordinator. ${ }^{55}$

Based on the information, the healthcare team may provide athletes with thorough education on the overall recovery process in easily understandable ways, create and discuss individualized treatment plans and goals with the patient, and ensure one-on-one attention during their sessions. Postoperative rehabilitation can be frustrating and mentally challenging for the ordinarily active young athlete, especially in the early stages when the athlete performs relatively basic exercises. Incorporating sport-specific exercises throughout the recovery process and providing the athlete with challenging workouts with aerobic conditioning, involving the upper extremities or the uninjured leg within safe constraints can help motivate and keep them engaged. Providing the athlete with concrete short-term goals (e.g., l session or 1 week) and assessing them with the patient may also help them navigate the uncertainty they may have about their progress and motivate them for the next goal. Although it is common for youth athletes and rehabilitation specialists to become impatient and frustrated with the slow progress, adhering to both time- and criterionbased progression is advocated. ${ }^{36}$

\section{Rehabilitation is Slower in the Youth Athlete}

Recovery for the youth athlete after ACLR is typically slower than that of an adult because of postsurgical precautions, slower strength gains, and psychological factors. Physeal-respecting surgeries frequently have weightbearing and range of motion restrictions, ${ }^{10,36}$ contributing to a longer rehabilitation duration. Concomitant procedures to the meniscus or the articular cartilage can further prolong this process.

Quadriceps strength deficit is related to altered knee mechanics, greater limb asymmetry, altered landing patterns, $^{56}$ and decreased function ${ }^{57}$ after ACLR. Delayed strength recovery is reported in all age groups in the pediatric population. In preadolescent athletes who underwent all-epiphyseal physeal-sparing ACLR, only $56 \%$ of athletes achieved $90 \%$ quad strength symmetry at 7 months after ACLR whereas $94 \%$ of athletes achieved adequate hamstring strength. ${ }^{58}$ In contrast, a separate study of pediatric athletes who underwent the same surgery reported that $69 \%$ of athletes met $90 \%$ limb symmetry for quadriceps strength, whereas only $38 \%$ met the cutoff for hamstring strength. ${ }^{59}$ Difficulty regaining strength is also reported in adolescents, with only $59 \%$ of athletes (mean age 15 ) achieving $\geq 85 \%$ quadriceps symmetry within 6 months. ${ }^{60}$ Additionally, in older adolescents (mean age 17) who were cleared for unrestricted sports, only $43.5 \%$ to $56 \%$ met the cutoff of $85 \%$ to $90 \%$ quadriceps strength symmetry. ${ }^{56,57,61}$

Although the cause of this delay in strength recovery is unclear, it is thought that physiological and psychological factors contribute. Training-induced strength improvements can be achieved in prepubescent children. ${ }^{62,63}$ However, strength gain is likely related to improved motor unit recruitment and neural adaptations rather than muscle hypertrophy ${ }^{64,65}$ because they lack androgenic hormones. ${ }^{6,67}$ Thus, in this age group, dynamic multijoint neuromuscular control should be the primary focus in rehabilitation. ${ }^{49}$ In adolescence, there is an increase in circulating androgens ${ }^{66}$; therefore rehabilitation can more closely resemble that of an adult. ${ }^{49}$

As discussed previously, increased postoperative pain and anxiety may contribute to slow recovery of strength and functional progression. Furthermore, psychological readiness is increasingly recognized as influencing RTS after ACLR. ${ }^{68-72}$ Paterno et al. $^{73}$ reported those with greater self-reported fear, using the Tampa Scale of Kinesiophobia, demonstrated decreased single-leg hop performance, isometric quadriceps strength, and had an increased risk of ipsilateral reinjury in the 24 months after ACLR. McPherson et al. $^{74}$ reported those with minor improvement in psychological readiness from preoperative to the 12-month mark, as measured by ACL-Return to Sport after Injury (ACL-RSI), were associated with a second ACL injury in younger patients. Although the specific recommendations of psychological interventions is beyond the scope of this article and can be found elsewhere, ${ }^{75}$ it is important for clinicians to address psychological factors throughout the rehabilitation process. 


\section{Return to Sport Testing for the Youth}

Most agree on using a battery of tests to assess RTS readiness, including muscle strength tests, functional tests such as hop tests, movement quality, and patientreported outcome measures (PROMs). ${ }^{76-78}$ Limb symmetry index $\geq 90 \%$ is a frequently reported criterion for strength and functional tests. Still, only $13 \%$ to $25 \%$ meet the passing combined criteria in this population after ACLR. ${ }^{58,61}$ Interestingly, Greenberg et al. ${ }^{79}$ reported that although a high proportion of uninjured youth athletes achieved passing performance on isolated hop tests, only $45 \%$ achieved $\geq 90 \%$ limb symmetry index across all four hop tests. These studies suggest that hop tests should be used with caution in this population.

The use of the uninvolved limb as a reference standard for symmetry presents its own problem. It does not reflect preinjury levels and may overestimate knee function after $\mathrm{ACLR}^{80}$ because of contralateral leg detraining, or the leg was weaker to begin with. The contralateral leg may be best tested before surgery for a more accurate benchmark. ${ }^{81}$

In addition to quantitative measures, quality of movement should be assessed as part of the RTS decision-making process. Decreased neuromuscular control has been related to ACL injury, reinjury, and decreased knee function. ${ }^{82-84}$ Movements such as squat, step down, single leg squat, drop vertical jump, tuck jump, deceleration, shuffle, single leg hop, and cutting are commonly used to assess kinematics and loading symmetry. $^{85,86}$ There is currently no standardized testing procedure for the pediatric athlete, and protocols created for the adult may lead to inaccurate results. Children may require verbal and visual demonstrations of the tasks, repeated several times, as well as specific instructions so that they clearly understand what they are asked to do. Different testing criteria and testing procedure may be necessary for the youth athlete.

Physical tests alone do not provide a complete picture of an athlete's readiness to RTS. PROMs offer insight into patient's perception of recovery and are an integral component of information in addition to objective clinical data throughout the recovery process. Phillips reported PROMs are underused and misused in the pediatric orthopaedic literature. ${ }^{87}$ Fabricant found the use of PROMs to evaluate pediatric ACLR is neither standardized nor validated for the population. ${ }^{88}$ The Lysholm, International Knee Documentation Committee Subjective Knee form (IKDC), Tegner Activity Scale, and Knee Injury and Osteoarthritis Outcome Score (KOOS) are frequently reported PROMs in the pediatric ACL literature, ${ }^{88,89}$ but none are designed for nor validated in the pediatric population. The use of adult PROMs in children has been shown to cause comprehensibility problems and should be avoided. ${ }^{90}$
Therefore, whenever possible, the use of pediatric PROMs is recommended, such as the Pedi-IKDC ${ }^{91,92}$ or KOOS-Child ${ }^{93}$ to assess self-reported knee function, and the Hospital for Special Surgery Pediatric Functional Activity Brief Scale (HSS Pedi-FABS) ${ }^{94}$ to assess self-reported activity level. The Child Health Questionnaire, ${ }^{95}$ Peds QL, ${ }^{96}$ or the Pediatric PROMIS ${ }^{97}$ may be used to assess QOL.

Incorporating psychological readiness and kinesiophobia assessment into a battery of RTS tests can further assist clinicians in RTS decision-making. The ACL-RSI assesses emotion, confidence, and risk appraisal and has been related to decision to RTS. ${ }^{98}$ Additionally, a cutoff score of 76.7 points was $90 \%$ sensitive to identify younger patients who suffered a second ACL injury. ${ }^{99}$ ACL-RSI is valid from 16 years of age. ${ }^{98}$ The Tampa Scale of Kinesiophobia assesses painrelated fear or movement or reinjury and has been used in previous studies after ACLR. ${ }^{73,100}$ However, it is important to note that the instrument has not been validated for children after ACLR.

\section{Reinjury Rate is High in the Youth}

Testing both physical and psychological readiness is important before RTS because reinjury rate is high. More than $90 \%$ of pediatric athletes return to sport after ACLR, with up to $81 \%$ returning to competitivelevel sport at the preinjury level. ${ }^{15,101}$ However, the rate of a second ACL injury in this population is as high as 32\%. ${ }^{17,102-104}$ The risk is highest within the first 2 years after ACLR. ${ }^{17,105}$ Unfortunately, the contralateral injury rate in this population is also increased, at 7\% to $20.5 \% .^{16,17,103,106-108}$ Reasons for a second ACL injury to either knee is multifactorial. Non-modifiable factors include graft type, ${ }^{20,109,110}$ age younger than 15 to $16,{ }^{106,111}$ female sex, ${ }^{106}$ and anatomic factors. ${ }^{112-114}$ Modifiable factors include returning to high-risk sports $^{115}$ and biomechanical and neuromuscular

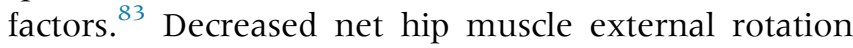
torque, increased dynamic valgus during landing, asymmetries in internal knee extensor moment at initial contact, and decreased single-leg postural stability at the time of RTS predicts second ACL injury to either knee. ${ }^{83}$ These neuromuscular deficits are similar to primary ACL injury risk. ${ }^{29}$

Neuromuscular training (NMT) effectively improves landing mechanics and performance and has shown to reduce ACL injury rate in healthy adolescents. ${ }^{16-121}$ Therefore NMT program should be an important component of rehabilitation after ACLR to reduce the risk of a second injury to the ipsilateral leg and to the contralateral leg. NMT effectiveness on preventing ACL injury has been shown to be dose-dependent and should be performed longer than 20 minutes in duration, more than 2 times per week. ${ }^{122}$ Incorporating 
various types of exercises such as plyometrics, balance training, trunk stabilization, and posterior chain strengthening exercises optimize the effects of NMT. ${ }^{122}$

Clinic-based rehabilitation may not represent the same conditions athletes experience on the field or court during sports. Therefore youth athletes may benefit from a more performance-based, sports-specific RTS training before unrestricted sports participation. On-field rehabilitation and RTS training programs have been shown to successfully improve muscle strength and knee function and reduce the risk of reinjury after ACLR. ${ }^{123-125}$ Important elements include restoring movement quality, physical conditioning, sport-specific skills, and load management. ${ }^{126}$ This may be best performed working with a performance specialist or team coach. Communication of all key stakeholders (athlete, coach, parents/guardians, healthcare providers) is crucial to monitor the progress of the program and assist the athlete's safe RTS. A more rigorous RTS training program that bridges the gap between rehabilitation and unrestricted sports may improve outcomes after ACLR in the youth.

\section{Time to Return to Sport is Later in Youth Athletes}

Many young athletes expect to RTS much sooner than the expected timeline. ${ }^{127}$ There are considerable differences in the literature regarding time to RTS in this population, and the appropriate time to return to play is currently unknown. Earlier RTS has been shown to be predictive of a second ACL injury in youth athletes. ${ }^{16}$ ACL reinjury rate was reduced by $51 \%$ for each month RTS was delayed until 9 months after surgery. ${ }^{128}$ Additionally, young athletes who returned to sport earlier than nine months had a 7-fold higher rate of second ACL injury than those who returned to sport after 9 months. ${ }^{129}$ The International Olympic Committee recommends youth athletes delay returning to pivoting sport until at least 12 months, ${ }^{49}$ and Nagelli and Hewitt ${ }^{130}$ proposed that young athletes delay RTS for two years based on biological healing, resolution of symptoms, and functional recovery. Based on the present information, RTS may be considered beginning at 9 months and can be as late as 2 years, along with satisfactory objective clinical data, movement quality, and psychological readiness. Healthcare providers should educate the athlete and their families regarding realistic expectations for time to RTS and risks of returning to sport too soon in a manner that is easily understandable before surgery.

It is important to note that many articles on pediatric and adolescent ACL injuries are of level IV evidence. Moreover, most are published after 2000 with shortterm follow-up. Therefore the long-term functional outcome and QOL are largely unknown.

\section{Conclusion}

Successfully returning a youth athlete to sport after ACLR requires knowledge and appreciation of various aspects of the growing athlete different from adults. In addition to postoperative precautions that contribute to a slow rehabilitation process, young athletes need additional time for strength gains. Address risk of reinjury and for contralateral injury by using neuromuscular training and rigorous return to sport training programs. Consider return to sport after 9 months as reinjury rate is high in this population. A combination of time and objective measures, both quantitative and qualitative criteria, and psychological readiness should be used to assess readiness to return to sport and decrease risk of future injury. Healthcare providers should be aware of the psychosocial impact of injury on the youth athletes and refer to sport psychology when necessary.

\section{References}

1. Bloom DA, Wolfert AJ, Michalowitz A, Jazrawi LM, Carter CW. ACL injuries aren't just for girls: The role of age in predicting pediatric ACL injury. Sports Health 2020;12:559-563.

2. Tepolt FA, Feldman L, Kocher MS. Trends in pediatric ACL reconstruction from the PHIS database. J Pediatr Orthop 2018;38:e490-e494.

3. Beck NA, Lawrence JTR, Nordin JD, DeFor TA, Tompkins M. ACL tears in school-aged children and adolescents over 20 years. Pediatrics 2017;139:e20161877.

4. Werner BC, Yang S, Looney AM, Gwathmey FW. Trends in pediatric and adolescent anterior cruciate ligament injury and reconstruction. J Pediatr Orthop 2016;36: 447-452.

5. Buller LT, Best MJ, Baraga MG, Kaplan LD. Trends in anterior cruciate ligament reconstruction in the United States. Orthop J Sport Med 2015;3:1-8.

6. Dodwell ER, Lamont LE, Green DW, Pan TJ, Marx RG, Lyman S. 20 years of pediatric anterior cruciate ligament reconstruction in New York state. Am J Sports Med 2014; $42: 675-680$.

7. Mall NA, Chalmers PN, Moric M, et al. Incidence and trends of anterior cruciate ligament reconstruction in the United States. Am J Sports Med 2014;42:2363-2370.

8. Parkkari J, Pasanen K, Manila VM, Kannus P, Rimpelä A. The risk for a cruciate ligament injury of the knee in adolescents and young adults: A population-based cohort study of 46,500 people with a 9 year follow-up. Br J Sports Med 2008;42:422-426.

9. Field AE, Tepolt FA, Yang DS, Kocher MS. Injury risk associated with sports specialization and activity volume in youth. Orthop J Sport Med 2019;7(9):2325967119870124.

10. Fabricant PD, Kocher MS. Anterior cruciate ligament injuries in children and adolescents. Orthop Clin North Am 2016:47:777-788.

11. James EW, Dawkins BJ, Schachne JM, et al. Early operative versus delayed operative versus nonoperative treatment of pediatric and adolescent anterior cruciate 
ligament injuries: A systematic review and meta-analysis. Am J Sports Med 2021;49:4008-4017.

12. Fabricant PD, Jones KJ, Delos D, et al. Reconstruction of the anterior cruciate ligament in the skeletally immature athlete: A review of current concepts AAOS exhibit selection. J Bone Jt Surg A 2013;95:e28.

13. Kocher M, Heyworth B, Fabricant P, Tepolt F, Micheli L. Outcomes of physeal-sparing ACL reconstruction with iliotibial band autograft in skeletally immature prepubescent children. J Bone Joint Surg Am 2018;100: 1087-1094.

14. Fabricant PD, Lakomkin N, Cruz AI, Spitzer E, Lawrence JTR, Marx RG. Early ACL reconstruction in children leads to less meniscal and articular cartilage damage when compared with conservative or delayed treatment. J ISAKOS Jt Disord Orthop Sport Med 2016;1: $10-15$.

15. Kay J, Memon M, Marx RG, Peterson D, Simunovic N, Ayeni OR. Over $90 \%$ of children and adolescents return to sport after anterior cruciate ligament reconstruction: A systematic review and meta-analysis. Knee Surg Sport Traumatol Arthrosc 2018;26:1019-1036.

16. Dekker TJ, Godin JA, Dale KM, Garrett WE, Taylor DC, Riboh JC. Return to sport after pediatric anterior cruciate ligament reconstruction and its effect on subsequent anterior cruciate ligament injury. J Bone Jt Surg Am 2017;99:897-904.

17. Paterno MV, Rauh MJ, Schmitt LC, Ford KR, Hewett TE. Incidence of second ACL injuries 2 years after primary ACL reconstruction and return to sport. Am J Sports Med 2014;42:1567-1573.

18. Christino MA, Tepolt FA, Sugimoto D, Micheli LJ, Kocher MS. Revision ACL reconstruction in children and adolescents. J Pediatr Orthop 2020;40:129-134.

19. Ouillette R, Edmonds E, Chambers H, Bastrom T, Pennock A. Outcomes of revision anterior cruciate ligament surgery in adolescents. Am J Sports Med 2019;47: 1346-1352.

20. Rugg CM, Pitcher AA, Allen C, Pandya NK. Revision ACL reconstruction in adolescent patients. Orthop J Sport Med 2020;8:2325967120953337.

21. Brenner JS, LaBella CR, Brooks MA, et al. Sports specialization and intensive training in young athletes. Pediatrics 2016;138:e20162148.

22. Shea KG, Pfeiffer R, Jo HW, Curtin M, Apel PJ. Anterior cruciate ligament injury in pediatric and adolescent soccer players: An analysis of insurance data. J Pediatr Orthop 2004;24:623-628.

23. Kaeding CC, Flanigan D, Donaldson C. Surgical techniques and outcomes after anterior cruciate ligament reconstruction in preadolescent patients. Arthroscopy 2010;26:1530-1538.

24. Stracciolini A, Stein CJ, Zurakowski D, et al. Anterior cruciate ligament injuries in pediatric athletes presenting to sports medicine clinic: A comparison of males and females through growth and development. Sports Health 2015;7:130-136.

25. Prince J, Laor T, Bean J. MRI of anterior cruciate ligament injuries and associated findings in the pediatric knee: Changes with skeletal maturation. AJR Am J Roentgenol 2005;185:756-762.
26. LaBella CR, Hennrikus W, Hewett TE, et al. Anterior cruciate ligament injuries: Diagnosis, treatment, and prevention. Pediatrics 2014;133:e1437-e1450.

27. Ford KR, Myer GD, Hewett TE. Longitudinal effects of maturation on lower extremity joint stiffness in adolescent athletes. Am J Sports Med 2010;38:1829-1837.

28. Ford KR, Shapiro R, Myer GD, Bogert AJ van den, Hewett TE. Longitudinal sex differences during landing in knee abduction in young athletes. Med Sci Sports Exerc 2010;42:1923-1931.

29. Hewett TE, Myer GD, Ford KR. Biomechanical measures of neuromuscular control and valgus loading of the knee predict anterior cruciate ligament injury risk in female athletes: A prospective study. Am J Sports Med 2005;33: 492-501.

30. Hewett TE, Myer GD, Ford KR. Decrease in neuromuscular control about the knee with maturation in female athletes. J Bone Jt Surg Am 2004;86:1601-1608.

31. Quatman-Yates CC, Quatman CE, Meszaros AJ, Paterno MV, Hewett TE. A systematic review of sensorimotor function during adolescence: A developmental stage of increased motor awkwardness? Br J Sports Med 2012;46:649-655.

32. Cordasco F, Mayer S, Green D. All-inside, all-epiphyseal anterior cruciate ligament reconstruction in skeletally immature athletes: Return to sport, incidence of second surgery, and 2-year clinical outcomes. Am J Sports Med 2017;45:856-863.

33. Fabricant PD, Lakomkin N, Cruz AI, Spitzer E, Marx RG. ACL reconstruction in youth athletes results in an improved rate of return to athletic activity when compared with non-operative treatment: A systematic review of the literature. J ISAKOS Jt Disord Orthop Sport Med 2016;1:62-69.

34. Ramski D, Kanj W, Franklin C, Baldwin K, Ganley T. Anterior cruciate ligament tears in children and adolescents: A meta-analysis of nonoperative versus operative treatment. Am J Sports Med 2014;42:2769-2776.

35. Frosch K, Stengel D, Brodhun T, et al. Outcomes and risks of operative treatment of rupture of the anterior cruciate ligament in children and adolescents. Arthroscopy 2010;26:1539-1550.

36. Yellin J, Fabricant P, Gornitzky A, et al. Rehabilitation following anterior cruciate ligament tears in children. JBJS Rev 2016;4:e4.

37. Christie D, Viner R. ABC of adolescence: Adolescent development. BMJ 2005;330:301-304.

38. McGuine TA, Winterstein AP, Carr K, Hetzel S. Changes in health-related quality of life and knee function after knee injury in young female athletes. Orthop J Sport Med 2014;2:2325967114530988.

39. Mcguine TA, Winterstein A, Carr K, Hetzel S, Scott J. Changes in self-reported knee function and healthrelated quality of life after knee injury in female athletes. Clin J Sport Med 2012;22:334-340.

40. Watson A, Biese K, Kliethermes SA, et al. Impact of inseason injury on quality of life and sleep duration in female youth volleyball athletes: A prospective study of 2073 players. Br J Sport Med 2021;55:912-916.

41. Boykin RE, McFeely ED, Shearer D, et al. Correlation between the child health questionnaire and the 
international knee documentation committee score in pediatric and adolescent patients with an anterior cruciate ligament tear. J Pediatr Orthop 2013;33:216-220.

42. Disanti J, Lisee C, Erickson K, Bell D, Shingles M, Kuenze C. Perceptions of rehabilitation and return to sport among high school athletes with anterior cruciate ligament reconstruction: A qualitative research study. J Orthop Sports Phys Ther 2018;48:951-959.

43. Von Rosen P, Kottorp A, Fridén C, Frohm A, Heijne A. Young, talented and injured: Injury perceptions, experiences and consequences in adolescent elite athletes. Eur J Sport Sci 2018;18:731-740.

44. Podlog L, Heil J, Schulte S. Psychosocial factors in sports injury rehabilitation and return to play. Phys Med Rehabil Clin N Am 2014;25:915-930.

45. Trentacosta N, Vitale M, Ahmad C. The effects of timing of pediatric knee ligament surgery on short-term academic performance in school-aged athletes. Am J Sports Med 2009;37:1684-1691.

46. Putukian M. The psychological response to injury in student athletes: A narrative review with a focus on mental health. Br J Sports Med 2016;50:145-148.

47. Renton T, Petersen B, Kennedy S. Investigating correlates of athletic identity and sport-related injury outcomes: A scoping review. BMJ Open 2021;11:e044199.

48. Padaki AS, Noticewala MS, Levine WN, Ahmad CS, Popkin MK, Popkin CA. Prevalence of posttraumatic stress disorder symptoms among young athletes after anterior cruciate ligament rupture. Orthop J Sport Med 2018;6:2325967118787159.

49. Ardern CL, Ekås GR, Grindem H, et al. 2018 International Olympic Committee consensus statement on prevention, diagnosis and management of paediatric anterior cruciate ligament (ACL) injuries. Br J Sports Med 2018;52:422-438.

50. Manuel JC, Shilt JS, Curl WW, et al. Coping with sports injuries: An examination of the adolescent athlete. J Adolesc Heal 2002;31:391-393.

51. Chieng Y, Chan W, Klainin-Yobas P, He H. Perioperative anxiety and postoperative pain in children and adolescents undergoing elective surgical procedures: A quantitative systematic review. J Adv Nurs 2014;70:243-255.

52. Kain Z, Mayes L, Weisman S, Hofstadter M. Social adaptability, cognitive abilities, and other predictors for children's reactions to surgery. J Clin Anesth 2000;12: 549-554.

53. Kain Z, Mayes L, O'Connor T, Cicchetti D. Preoperative anxiety in children. Predictors and outcomes. Arch Pediatr Adolesc Med 1996;150:1238-1245.

54. Rabbitts J, Groenewalkd C, Tai G, Palermo T. Presurgical psychosocial predictors of acute postsurgical pain and quality of life in children undergoing major surgery. J Pain 2015;16:226-234.

55. Paterno MV, Schmitt LC, Thomas S, Duke N, Russo R, Quatman-Yates CC. Patient and parent perceptions of rehabilitation factors that influence outcomes after anterior cruciate ligament reconstruction and clearance to return to sport in adolescents and young adults. J Orthop Sports Phys Ther 2019;49:576-583.

56. Schmitt L, Paterno M, Ford K, Myer G, Hewett T. Strength asymmetry and landing mechanics at return to sport after ACL reconstruction. Med Sci Sport Exerc 2015;47:1426-1434.

57. Schmitt L, Paterno M, Hewett T. The impact of quadriceps femoris strength asymmetry on functional performance at return to sport following anterior cruciate ligament reconstruction. J Orthop Sports Phys Ther 2012;42:750-759.

58. Greenberg EM, Greenberg ET, Ganley TJ, Lawrence JTR. Strength and functional performance recovery after anterior cruciate ligament reconstruction in preadolescent athletes. Sports Health 2014;6:309-312.

59. Ithurburn MP, Paljieg A, Thomas S, Hewett TE, Paterno MV, Schmitt LC. Strength and function across maturational levels in young athletes at the time of return to sport after ACL reconstruction. Sports Health 2019;11:324-331.

60. Wells L, Dyke JA, Albaugh J, Ganley T. Adolescent anterior cruciate ligament reconstruction: A retrospective analysis of quadriceps strength recovery and return to full activity after surgery. J Pediatr Orthop 2009;29: 486-489.

61. Toole AR, Ithurburn MP, Rauh MJ, Hewett TE, Paterno MV, Schmitt LC. Young athletes cleared for sports participation after anterior cruciate ligament reconstruction: How many actually meet recommended return-to-sport criterion cutoffs? J Orthop Sports Phys Ther 2017;47:825-833.

62. Granacher U, Goesele A, Roggo K, et al. Effects and mechanisms of strength training in children. Int J Sports Med $2011 ; 32: 357-364$.

63. Behringer M, Heede A vom, Matthews M, Mester J. Effects of strength training on motor performance skills in children and adolescents: A meta-analysis. Pediatr Exerc Sci 2011;23:186-206.

64. Ramsay J, Blimkie C, Smith K, Garner S, MacDougall J, Sale D. Strength training effects in prepubescent boys. Med Sci Sports Exerc 1990;22:605-614.

65. Lloyd RS, Oliver JL. The youth physical development model: A new approach to long-term athletic development. Strength Cond J 2012;34:61-72.

66. Murray P, Playton P. Endocrine control of growth. Am J Med Genet C Semin Med Genet 2013;163C(2):76-85.

67. Round J, Jones D, Honour J, Nevill A. Hormonal factors in the development of differences in strength between boys and girls during adolescence: A longitudinal study. Ann Hum Biol 1999;26:49-62.

68. Kaplan Y, Witvrouw E. When is it safe to return to sport after ACL reconstruction? Reviewing the criteria. Sports Health 2019;11:301-305.

69. Christino MA, Fantry AJ, Vopat BG. Psychological aspects of recovery following anterior cruciate ligament reconstruction. J Am Acad Orthop Surg 2015;23: 501-509.

70. Ardern CL, Taylor NF, Feller JA, Whitehead TS, Webster KE. Psychological responses matter in returning to preinjury level of sport after anterior cruciate ligament reconstruction surgery. Am J Sports Med 2013;41: 1549-1558.

71. McCullough K, Phelps K, Spindler K, et al. Return to high school- and college-level football after anterior cruciate ligament reconstruction: A Multicenter 
Orthopaedic Outcomes Network (MOON) cohort study. Am J Sports Med 2012;40:2523-2529.

72. Kvist J, Ek A, Sporrstedt K, Good L. Fear of re-injury: A hindrance for returning to sports after anterior cruciate ligament reconstruction. Knee Surg Sport Traumatol Arthrosc 2005;13:393-397.

73. Paterno MV, Flynn K, Thomas S, Schmitt LC. Self-reported fear predicts functional performance and second ACL Injury after ACL reconstruction and return to sport: A pilot study. Sports Health 2018;10:228-233.

74. McPherson AL, Feller JA, Hewett TE, Webster KE. Smaller change in psychological readiness to return to sport is associated with second anterior cruciate ligament injury among younger patients. Am J Sports Med 2019;47: 1209-1215.

75. te Wierike SCM, van der Sluis A, van den AkkerScheek I, Elferink-Gemser MT, Visscher C. Psychosocial factors influencing the recovery of athletes with anterior cruciate ligament injury: A systematic review. Scand J Med Sci Sport 2013;23:527-540.

76. Dietvorst M, Brzoskowski $\mathrm{MH}$, van der Steen M, Delvaux E, Janssen RPA, Van Melick N. Limited evidence for return to sport testing after ACL reconstruction in children and adolescents under 16 years: A scoping review. J Exp Orthop 2020;7:83.

77. Capin JJ, Snyder-Mackler L, Risberg MA, Grindem H. Keep calm and carry on testing: A substantive reanalysis and critique of "What is the evidence for and validity of return-to-sport testing after anterior cruciate ligament reconstruction surgery? A systematic review and meta-analysis." Br J Sports Med 2019;53: 1444-1446.

78. Burgi CR, Peters S, Ardern CL, et al. Which criteria are used to clear patients to return to sport after primary ACL reconstruction? A scoping review. Br J Sports Med 2019;53:1154-1161.

79. Greenberg EM, Dyke J, Leung A, Karl M, Lawrence JT, Ganley T. Uninjured youth athlete performance on single-leg hop testing: How many can achieve recommended return-to-sport criterion? Sports Health 2020;12: 552-558.

80. Wellsandt E, Failla M, Snyder-Mackler L. Limb symmetry indexes can overestimate knee function after ACL injury. J Orthop Sports Phys Ther 2017;47:334-338.

81. Davies WT, Myer GD, Read PJ. Is it time we better understood the tests we are using for return to sport decision making following ACL reconstruction? A critical review of the hop tests. Sport Med 2020;50:485-495.

82. Ithurburn MP, Paterno MV, Ford KR, Hewett TE, Schmitt LC. Young athletes after anterior cruciate ligament reconstruction with single-leg landing asymmetries at the time of return to sport demonstrate decreased knee function 2 years later. Am J Sports Med 2017;45: 2604-2613.

83. Paterno MV, Schmitt LC, Ford KR, et al. Biomechanical measures during landing and postural stability predict second anterior cruciate ligament injury after anterior cruciate ligament reconstruction and return to sport. Am J Sports Med 2010;38:1968-1978.

84. Pollard CD, Sigward SM, Powers CM. Limited hip and knee flexion during landing is associated with increased frontal plane knee motion and moments. Clin Biomech (Bristol, Avon) 2010;25:142-146.

85. Ellington MD, Randich K, Garfin J, et al. Interrater and intrarater reliability and discriminant validity of a pediatric lower extremity physical therapy clearance test. Orthop J Sport Med 2021;9:2325967120983827.

86. Graziano J, Chiaia T, De Mille P, Nawabi DH, Green DW, Cordasco FA. Return to sport for skeletally immature athletes after ACL reconstruction: Preventing a second injury using a quality of movement assessment and quantitative measures to address modifiable risk factors. Orthop J Sport Med 2017;5:2325967117700599.

87. Phillips L, Carsen S, Vasireddi A, Mulpuri K. Use of patient-reported outcome measures in pediatric orthopaedic literature. J Pediatr Orthop 2018;38:393-397.

88. Fabricant PD, Brusalis CM, Schachne JM, et al. Which metrics are being used to evaluate children and adolescents after ACL reconstruction? A systematic review. Arthrosc Sport Med Rehabil 2020;2:e417-e428.

89. Zebis MK, Warming S, Pedersen MB, et al. Outcome measures after ACL Injury in pediatric patients: A scoping review. Orthop J Sport Med 2019;7: 2325967119861803.

90. Dietvorst M, Reijman M, Groningen B van, Steen MC van der, Janssen RPA. PROMs in paediatric knee ligament injury: Use the Pedi-IKDC and avoid using adult PROMs. Knee Surg Sport Traumatol Arthrosc 2019;27: 1965-1973.

91. Kocher M, Smith J, Iversen M, et al. Reliability, validity, and responsiveness of a modified International Knee Documentation Committee Subjective Knee Form (PediIKDC) in children with knee disorders. Am J Sports Med $2011 ; 39: 933-939$.

92. van der Velden C, van der Steen M, Leenders J, van Douveren F, Janssen R, Reijman M. Pedi-IKDC or KOOS-child: Which questionnaire should be used in children with knee disorders? BMC Musculoskelet Disord 2019;20:240.

93. Ortqvist M, Iversen M, Janarv P, Broström E, Roos E. Psychometric properties of the Knee injury and Osteoarthritis Outcome Score for Children (KOOS-Child) in children with knee disorders. Br J Sports Med 2014;48: 1437-1446.

94. Fabricant P, Robles A, Downey-Zayas T, et al. Development and validation of a pediatric sports activity rating scale: The Hospital for Special Surgery Pediatric Functional Activity Brief Scale (HSS Pedi-FABS). Am J Sports Med 2013;41:2421-2429.

95. Hullmann S, Ryan J, Ramsey R, Chaney J, Mullins L. Measures of general pediatric quality of life: Child Health Questionnaire (CHQ), DISABKIDS Chronic Generic Measure (DCGM), KINDL-R, Pediatric Quality of Life Inventory (PedsQL) 4.0 Generic Core Scales, and Quality of My Life Questionnaire (QoML). Arthritis Care Res (Hoboken) 2011;63:S420-S430 (Suppl 1).

96. Varni J, Seid M, Rode C. The PedsQL: Measurement model for the pediatric quality of life inventory. Med Care 1999;37:126-139.

97. Irwin D, Varni J, Yeatts K, DeWalt D. Cognitive interviewing methodology in the development of a pediatric item bank: A patient reported outcomes measurement 
information system (PROMIS) study. Health Qual Life Outcomes 2009;7:3.

98. Webster KE, Feller JA, Lambros C. Development and preliminary validation of a scale to measure the psychological impact of returning to sport following anterior cruciate ligament reconstruction surgery. Phys Ther Sport 2008;9:9-15.

99. McPherson AL, Feller JA, Hewett TE, Webster KE. Psychological readiness to return to sport Is associated with second anterior cruciate ligament injuries. Am J Sports Med 2019;47:857-862.

100. George SZ, Lentz TA, Zeppieri GJ, Lee D, Chmielewski TL. Analysis of shortened versions of the Tampa Scale for Kinesiophobia and Pain Catastrophizing Scale for patients following anterior cruciate ligament reconstruction. Clin J Pain 2012;28:73-80.

101. Morvan A, Bouguennec N, Graveleau N. ACL injuries before 15 years of age: Could the young become an athlete? Arch Orthop Trauma Surg 2020;140:1055-1063.

102. Wiggins A, Grandhi R, Schneider D, Stanfield D, Webster K, Myer G. Risk of secondary injury in younger athletes after anterior cruciate ligament reconstruction: A systematic review and meta-analysis. Am J Sport Med 2016;44:1861-1876.

103. Paterno MV, Rauh MJ, Schmitt LC, Ford KR, Hewett TE. Incidence of contralateral and ipsilateral anterior cruciate ligament (ACL) injury after primary ACL reconstruction and return to sport. Clin J Sport Med 2012;22: 116-121.

104. Webster KE, Feller JA, Leigh WB, Richmond AK. Younger patients are at increased risk for graft rupture and contralateral injury after anterior cruciate ligament reconstruction. Am J Sports Med 2014;42:641-647.

105. Webster KE, Feller JA. Exploring the high reinjury rate in younger patients undergoing anterior cruciate ligament reconstruction. Am J Sports Med 2016;44: 2827-2832.

106. Patel NM, Bram JT, Talathi NS, Defrancesco CJ, Lawrence JTR, Ganley TJ. Which children are at risk for contralateral anterior cruciate ligament injury after ipsilateral reconstruction? J Pediatr Orthop 2020;40: 162-167.

107. Ho B, Edmonds E, Chambers H, Bastrom T, Pennock A. Risk factors for early ACL reconstruction failure in pediatric and adolescent patients: A review of 561 cases. J Pediatr Orthop 2018;38:388-392.

108. DeFrancesco CJ, Storey EP, Flynn JM, Ganley TJ. Pediatric ACL reconstruction and return to the operating room: Revision Is less than half of the story. J Pediatr Orthop 2019;39:516-520.

109. Engelman G, Carry P, Hitt K, Polousky J, Vidal A. Comparison of allograft versus autograft anterior cruciate ligament reconstruction graft survival in an active adolescent cohort. Am J Sports Med 2014;42: $2311-2318$.

110. Ellis HB, Matheny LM, Briggs KK, Pennock AT, Steadman JR. Outcomes and revision rate after bonepatellar tendon-bone allograft versus autograft anterior cruciate ligament reconstruction in patients aged 18 years or younger with closed physes. Arthroscopy 2012;28:1819-1825.
111. Astur DC, Cachoeira CM, Vieira T da S, Debieux P, Kaleka CC, Cohen M. Increased incidence of anterior cruciate ligament revision surgery in paediatric verses adult population. Knee Surg Sport Traumatol Arthrosc 2017;26:1362-1366.

112. Dare D, Fabricant P, McCarthy M, et al. Increased lateral tibial slope is a risk factor for pediatric anterior cruciate ligament injury: An MRI-based case-control study of 152 patients. Am J Sports Med 2015;43:1632-1639.

113. O'Malley M, Milewski M, Solomito M, Erwteman A, Nissen C. The association of tibial slope and anterior cruciate ligament rupture in skeletally immature patients. Arthroscopy 2015;31:77-82.

114. Shaw K, Dunoski B, Mardis N, Pacicca D. Knee morphometric risk factors for acute anterior cruciate ligament injury in skeletally immature patients. J Child Orthop 2015;9:161-168.

115. Webster KE, Feller JA, Kimp AJ, Whitehead TS. Revision anterior cruciate ligament reconstruction outcomes in younger patients: Medial meniscal pathology and high rates of return to sport are associated with third ACL injuries. Am J Sports Med 2018;46:1137-1142.

116. Hewett TE, Lindenfeld T, Riccobene J, Noyes F. The effect of neuromuscular training on the incidence of knee injury in female athletes: A prospective study. Am J Sports Med 1999;27:699-706.

117. Noyes F, Barber-Westin S. Neuromuscular retraining intervention programs: Do they reduce noncontact anterior cruciate ligament injury rates in adolescent female athletes? Arthroscopy 2014;30:245-255.

118. Sugimoto D, Myer GD, Bush HM, Klugman MF, McKeon JMM, Hewett TE. Compliance with neuromuscular training and anterior cruciate ligament injury risk reduction in female athletes: A meta-analysis. J Athl Train 2012;47:714-723.

119. Myer G, Ford K, Palumbo J, Hewett T. Neuromuscular training improves performance and lower-extremity biomechanics in female athletes. J strength Cond Res 2005;19:51-60.

120. Hewett TE, Myer GD. Reducing knee and anterior cruciate ligament injuries among female athletes. J Knee Surg 2005;18:82-88.

121. Myer GD, Sugimoto D, Thomas S, Hewett TE. The influence of age on the effectiveness of neuromuscular training to reduce anterior cruciate ligament injury in female athletes: A meta-analysis. Am J Sports Med 2013;41:203-215.

122. D S, GD M, KD BF, MJ P, LJ M, TE H. Critical components of neuromuscular training to reduce ACL injury risk in female athletes: Meta-regression analysis. $\mathrm{Br} \mathrm{J}$ Sports Med 2016;50:1259-1266.

123. Della Villa S, Boldrini L, Ricci M, et al. Clinical outcomes and return-to-sports participation of 50 soccer players after anterior cruciate ligament reconstruction through a sportspecific rehabilitation protocol. Sports Health 2012;4:17-24.

124. Della Villa F, Ricci M, Perdisa F, et al. Anterior cruciate ligament reconstruction and rehabilitation: Predictors of functional outcome. Joints 2016;3:179-185.

125. Capin JJ, Failla M, Zarzycki R, et al. Superior 2-Year functional outcomes among young female athletes after ACL reconstruction in 10 return-to-sport training 
sessions: Comparison of ACL-SPORTS randomized controlled trial with Delaware-Oslo and MOON cohorts. Orthop J Sport Med 2019;7:2325967119861311.

126. Buckthorpe M, Villa F Della, Villa S Della, Roi GS. On-field rehabilitation part 1: 4 pillars of high-quality on-field rehabilitation are restoring movement quality, physical conditioning, restoring sport-specific skills, and progressively developing chronic training load. J Orthop Sports Phys Ther 2019;49:565-569.

127. Armento A, Albright J, Gagliardi A, Daoud AK, Howell D, Mayer S. Patient expectations and perceived social support related to return to sport after anterior cruciate ligament reconstruction in adolescent athletes. Phys Ther Sport 2021;47:72-77.
128. Grindem H, Snyder-Mackler L, Moksnes H, Engebretsen L, Risberg MA. Simple decision rules can reduce reinjury risk by $84 \%$ after ACL reconstruction: The Delaware-Oslo ACL cohort study. Br J Sports Med 2016;50:804-808.

129. Beischer S, Gustavsson L, Senorski E, et al. Young athletes who return to sport before 9 months after anterior cruciate ligament reconstruction have a rate of new injury 7 times that of those who delay return. J Orthop Sports Phys Ther 2020;50:83-90.

130. Nagelli CV, Hewett TE. Should return to sport be delayed until two years after anterior cruciate ligament reconstruction? Biological and functional considerations. Sport Med 2017;47:221-232. 